\title{
Configuration of Aerosol Delivery Devices and Their Placement: Let's Be Sure We're Paying Attention to the Literature
}

In this issue of RespiRatory CARe, Ball and colleagues ${ }^{1}$ determined the optimal nebulizer configurations and positions for aerosol delivery in vitro with and without CPAP. They determined that with continuous high-flow CPAP, the greatest amount of albuterol delivered to a lung simulator $(13.8 \pm 4.4 \%)$ was when the nebulizer was placed proximal to the lung simulator. Without CPAP, they determined that the greatest amount of albuterol delivered to the lung simulator $(9.9 \pm 1.1 \%)$ was with a T-piece with one extremity closed with a cap. Studies such as this are so important because practitioners may be complacent about the equipment setup and nebulizer position for delivering an aerosol to patients with or without mechanical ventilation, performing this therapy as they were shown by their clinical instructors or others, without regard for the actual aerosol delivery to the airways or outcome of the therapy as determined by careful patient assessment or by review of the literature on this topic. For instance, some practitioners may place the medication nebulizer in-line with a large volume air entrainment nebulizer. Unfortunately, the high flow of gas blows the medicated aerosol through the circuit such that virtually no medication reaches the patient. As therapists, we need to ensure that when we give an aerosol treatment, it's not just because it was ordered, but rather with attention to whether the aerosol actually makes it to the airway, whether it is indicated, and whether we have assessed the patient before and after the treatment to see if it was effective. We have the tools and assessment skills to do this.

We now know as the result of excellent research, both in vitro and in vivo, the correct placement of the nebulizer

Dr Op't Holt has disclosed no conflicts of interest.

Correspondence: Timothy B Op't Holt EdD RRT AE-C FAARC, Department of Cardiorespiratory Care, University of South Alabama, 5721 Drive North USA, Mobile, AL 36688-0002. E-mail: toptholt@ southalabama.edu.

DOI: $10.4187 /$ respcare.04699 for spontaneously breathing patients with and without artificial airways, ${ }^{1,2}$ and we know that a mouthpiece is the preferred interface. ${ }^{2}$ We know the correct placement of the

See the Original Study on Page 263

jet nebulizer ${ }^{3}$ and vibrating mesh nebulizer ${ }^{3}$ in patients being mechanically ventilated both invasively and noninvasively, ${ }^{4}$ and we know the correct type and placement of spacers when we give aerosol via a metered-dose inhaler in patients being ventilated ${ }^{3}$ or not. RESPIRATORY CARE and other publications ${ }^{5}$ do an excellent job of conveying this information, as do the many speakers at meetings. Let's be sure that therapists who may not take advantage of the current literature are receiving the message and adapting their practice to incorporate this information. It behooves educators, managers, and the therapist at the bedside to make this assurance for the good of the patient.

Timothy B Op't Holt EdD RRT AE-C FAARC Department of Cardiorespiratory Care University of South Alabama Mobile, Alabama

\section{REFERENCES}

1. Ball L, Sutherasan Y, Caratto V, Sanguineti E, Marsili M, Raimondo $\mathrm{P}$, et. al. Effect of nebulizer position, gas flow, and CPAP on aerosol bronchodilator delivery: an in vitro study. Respir Care 2016;61(3): 263-268.

2. Ari A, Restrepo RD. Aerosol delivery device selection for spontaneously breathing patients: 2012. Respir Care 2012;57(4):613-626.

3. Ari A, Fink JB, Dhand R. Inhalation therapy in patients receiving mechanical ventilation: an update. J Aerosol Med Pulm Drug Deliv 2012;25(6):319-332.

4. Dhand R. Aerosol therapy in patients receiving noninvasive positive pressure ventilation. J Aerosol Med Pulm Drug Deliv 2012;25(2): 63-78.

5. Hess DR. Humidity and aerosol therapy. In: Hess DR, MacIntyre NR, Galvin WF, Mishoe SC, editors. Respiratory Care: Principles and Practice, 3rd edition, Burlington MA: Jones and Bartlett; 2016: 307-351. 